\title{
TENDER OfFERS, PROXY CONTESTS, AND LARGE-SHAREHOLDER ACTIVISM
}

\author{
SUdiPTO DASGUPTA \\ Hong Kong University of Science and Technology \\ Hong Kong \\ dasgupta@usthk.ust.hk \\ VIKRAM NANDA \\ University of Michigan Business School \\ Ann Arbor, MI 48109-1234 \\ Vikram_nanda@ccmail.bus.umich.edu
}

The paper analyzes tender offers and proxy contests as alternative means of resolving corporate governance conflicts between dissidents and incumbent management. We show that when a dissident shareholder is sufficiently confident about the potential benefits from changing corporate policy, he will seek majority control by making a tender offer rather than initiating a proxy contest. When the dissident is relatively uninformed, however, he may opt for a proxy contest, thereby utilizing the information of other shareholders to implement the better policy. Consistent with empirical evidence, the model predicts that announcements of tender offers will tend to be associated with larger positive stock price reactions than announcements of proxy contests. The model is easily extended to allow for promanagement bias in proxy voting by institutional investors. Empirical observations that have been viewed as evidence of such promanagement bias are shown to be quite consistent with the absence of such bias. Policy issues are discussed as well. An interesting result is that even policies targeted at reducing the costs of conducting proxy contests may have ambiguous social consequences, given the possibility of substitution between tender offers and proxy contests.

\section{INTRODUCTION}

Unhappy with the corporate policies of incumbent management, dissident shareholders may initiate a proxy fight and oppose management's nominees to the company board. Alternatively, they may choose to

We thank Harry DeAngelo, Bruno Gerard, John Matsusaka, Nolan McCarty, Sheridan Titman, Dan Spulber (editor), the coeditor, and anonymous referees for helpful suggestions. We thank seminar participants at the University of Southern California and Hong Kong University of Science and Technology for their comments.

(C) 1997 Massachusetts Institute of Technology.

Journal of Economics \& Management Strategy, Volume 6, Number 4, Winter 1997, 787-820 
make a tender offer for a controlling share of the firm's common stock. Despite the common perception that corporate control contests usually take the form of hostile takeovers, studies have established that proxy contests are used almost as frequently as hostile tender offers and serve as an effective threat to incumbent management (DeAngelo and DeAngelo, 1989). ${ }^{1}$ In this paper we analyze the choice between proxy contests and tender offers as alternative means of resolving corporate governance conflicts between dissidents and incumbent management. While the existing literature has usually treated proxy contests and takeovers separately, we will argue that the possibility of substitution between the alternative mechanisms has important empirical and policy implications concerning corporate control issues. ${ }^{2}$

We analyze a situation in which a large dissident shareholder is challenging incumbent management on aspects of its corporate policy. The management is biased towards maintaining the status quo and is opposed to such change. ${ }^{3}$ The dissident shareholder, having (privately) uncovered information about the potential benefits from altering firm policy, can attempt to force change by either tendering for a majority of the outstanding shares or by soliciting votes from other shareholders in a proxy contest. This choice is shown to be strongly influenced by the nature of other shareholders in the firm. Though a majority of the firm's shareholders are assumed to be atomistic, large institutional investors are present as well. These institutional investors can be pivotal in control contests; on occasion they may also be better informed than the dissident about the potential benefits from changing firm policy.

Our model indicates that tender offers will tend to be employed when the dissident shareholder is relatively confident that the potential improvement in value is high. On the other hand, if the potential value

1. DeAngelo and DeAngelo (1989) provide evidence that between 1962 and 1983, there were a total of 141 proxy contests for board seats at listed firms, compared with 171 cases of hostile tender offers. Further, DeAngelo and DeAngelo dispel the notion that the proxy contest is an ineffective means of affecting change in control. In one-third of the cases they study, dissidents won control of the target board. In another one-third, they won minority representation. Dissidents played a major role in the sale/liquidation of assets and management turnover: often, they themselves bought the firms or replaced the incumbents as managers.

2. The substitution between alternative mechanisms and the information aggregation problem also underlie the analysis of boards of directors and takeovers as two monitors of management in Hirshleifer and Thakor (1994, 1996).

3. "Change" may involve divesting some existing projects. Shleifer and Vishny (1989) argue that managers may resist divestment if their human capital is sunk in existing projects or processes. Boot (1992) points out that managers may avoid divestiture out of reputational concerns. 
improvement is small or the large shareholder is relatively uninformed about the potential value improvement, then proxy contests will be employed. This feature of the model is reminiscent of the idea put forward by Pound $(1988,1991)$ that "Bidders who cannot increase value will try to gain control through proxy contests, while bidders who can add value will signal their seriousness through tender offers" (Pound, 1988). ${ }^{4}$ The model thus predicts that stock price reactions to tender offer announcements will tend to be more favorable than those for proxy contests. This is consistent with the empirical evidence [see DeAngelo and DeAngelo (1989) and Jarrell et al. (1988)].

We investigate the effect of various parameters on the choice between proxy contests and tender offers and their effect on firm value, as well as the magnitude of the price reactions following announcements of tender offers or proxy challenges. These results generate empirically testable implications.

Our analysis also indicates that the consequences of policy changes that affect the costs of conducting tender offers or proxy contests, or the voting behavior of institutional investors, need to be examined with caution. We stress two key points. One is that, since proxy contests and tender offers are alternative mechanisms for effecting change in corporate policy, changes in parameter values will often mean favoring one of these at the expense of the other. The implications for firm value will depend on whether, on the margin, tender offers or proxy contests are more desirable. Several counterintuitive possibilities are shown. For example, if the proxy process is not highly efficient (in the sense that the quality of information with passive investors is not high), then lowering the cost of conducting proxy challenges may not be desirable from a policy perspective, since inefficient proxy contests may crowd out more efficient tender offers. ${ }^{5}$

The second key point is that policy changes may have the effect of changing the voting behavior of institutional investors: from implicit reliance on the quality of the dissident's information in a proxy contest,

4. Our approach has some similarities to the model of Harris and Raviv (1988). In their paper as well, the proxy process is viewed as one in which the information of passive shareholders can be utilized to attain a better outcome for the firm in a control contest. The focus of Harris and Raviv (1988) is, however, on the role of capital structure in affecting the votes controlled by management.

5. Thus, whether or not increases in the cost of conducting proxy contests during a particular historical period (see Pound, 1991) and the associated decline in the use of proxy contests is undesirable depends on the quality of the information with the passive investors. 
to voting on the basis of their own information. Policy proposals such as those under the ERISA guidelines-requiring institutional investors to justify their voting practices-may well have such an effect. We argue that the consequences of such policy changes for firm value can be ambiguous, depending on the quality of the institutional investors' information. Also, to the extent higher ownership stakes increase the incentive to collect information, greater institutional ownership can result in a lower success rate and possibly less frequent use of proxy contests, but higher firm value. This is in contrast to Pound (1988), who finds proxy contests are less likely to be used (and less successfully) for firms with greater institutional ownership, but concludes this to be evidence in favor of "management bias" in the voting behavior of institutional investors, and thus symptomatic of inefficiency.

The rest of the paper is organized as follows. The model is developed in Sections 2 and 3. Empirical implications of the model and the comparative statics are discussed in Sections 4 and 5. The issue of promanagement bias in proxy voting and policy implications are in Sections 6 and 7. Section 8 concludes.

\section{THE MOdeL}

\subsection{PRELIMINARIES}

We follow Shleifer and Vishny (1986) in assuming that a fraction $\alpha$ of the shares of an all equity firm are held by a large shareholder, henceforth denoted $L .{ }^{6}$ Management owns a fraction $\gamma$ of the firm's equity, while the remaining shares are held by passive shareholders. The latter consist of dispersed atomistic shareholders and institutional investors. A majority, $\bar{\omega}>\frac{1}{2}$, of the outstanding shares are assumed to be owned by the dispersed atomistic shareholders. ${ }^{7}$ Note that this implies $\alpha+\gamma$ $<\frac{1}{2}$.

Let $q$ denote the value of the firm under current policy. $L$ invests some resources in monitoring the firm. This monitoring activity will

6. Aspects of our model are closely related to Shleifer and Vishny (1986), which analyzes the role of large shareholders in tender offers.

7. This assumption is made to ensure that the institutional shareholders are not pivotal in share-tendering outcomes. However, if the institutional shareholders are informed, it is possible that their presence could affect the share-tendering outcome in other ways. The information structure chosen for the model allows us to avoid such complications (see Section 2.3). 
result, with probability $\rho$, in $L$ identifying an alternative policy to the one being followed by incumbent management. ${ }^{8}$ Ex ante, the alternative policy will be assumed to enhance firm value by $z$, which is a random draw from a distribution $F(z)$. $F(z)$ is taken to be continuously differentiable with density $f(z)$ and support $[\underline{z}, \bar{z}]$, where $-\infty \leq z<0$ and $+\infty$ $\geq \bar{z}>0$. To simplify notation, we shall assume that $F(z)$ is symmetric around zero, so that $E(z)=0$, where $E(\cdot)$ denotes expected value. None of the results depend on this assumption. We also assume that $F(z)$ satisfies the increasing-hazard-rate property:

A1: $\frac{f(z)}{1-F(z)}$ is increasing in $z$.

As is well known, many standard distributions such as the normal or uniform satisfy this property. A1 is not crucial for our analysis; however, it simplifies the exposition.

As we shall discuss, the manner in which the large shareholder attempts to alter corporate policy can depend on the quality of his information about the benefits from adopting the alternative policy. We allow for heterogeneity in the quality of the information with the large shareholder by assuming that the information can be of two types. With probability $\mu, L$ has very precise information about the potential value improvement from the alternative policy that his monitoring has generated, i.e., he knows the true realized value of $z$. We say that in this case, $L$ is (perfectly) informed. With probability $1-\mu$, however, $L$ is relatively uninformed and knows only that $z$ is a random draw from $F(z)$.

Since our interest is in issues of corporate control, we will assume that the incumbent management has a vested interest in preserving the status quo and would resist change, even if it knew the alternative policy to be better. Possible reasons for this may be that management has its human capital or its reputation tied to current investment policies [see Shleifer and Vishny (1989) and Boot (1992)]. Further, the alternative policy might entail changing the management team or liquidating the firm, resulting in management losing its benefits from control.

8. The assumption that it is $L$, rather than an institutional investor, that initially investigates the firm and decides on the appropriate course of action is based on our desire to analyze the interaction between proxy contests and takeovers in equilibrium. Institutional investors such as pension funds and insurance companies are not in a position (on account of legal/charter restrictions and lack of managerial and operational expertise) to make tender offers and directly manage companies. In addition, even proxy contests are almost never initiated by institutional investors. One rare case is the 1990 proxy contest for XTRA that was initiated (and won) by Gintel Funds (a mutual fund). 
The implementation of the alternative policy may, therefore, require a new management without commitment to existing policies or, as the case might be, with an established reputation for successful liquidations. ${ }^{9}$ It may be unnecessary to dismiss incumbent management if a change in board composition, say from management-dominated to one vigilant about shareholder concerns, is sufficient to ensure the implementation of the alternative policy. ${ }^{10}$ For our discussion the assumption is that a change in corporate control is necessary to alter corporate policy, though management may or may not be dismissed subsequently.

Once an alternative policy is found, $L$ has three options: (a) do nothing, (b) make a tender offer for at least half the outstanding shares, or (c) initiate a proxy challenge. Apart from the information he obtains, $L$ 's choice will be influenced by the cost of making a tender offer $\left(c_{T}\right)$ compared to that of organizing a proxy contest $\left(c_{P}\right)$. We will assume throughout that

A2: $\quad c_{P}>c_{T}{ }^{11}$

Not all our results require this assumption. In the subsequent analysis, we shall indicate which of our results depend on it.

\subsection{PASSIVE SHAREHOLDER INFORMATION AND VOTING BEHAVIOR}

As mentioned above, passive shareholders are of two types: dispersed atomistic shareholders and institutional investors. The former are uninformed, while the latter are assumed to possess some information. We will assume that the ownership stake of institutional investors, as well as the quality of their information (prior to the control contest), is low enough to preclude them from initiating proxy contests, consistent with observed behavior. ${ }^{12}$ Another way to justify the passivity of institutional investors in the model is to argue that a significant amount of

9. Such a reputation may help overcome potential ex post problems if precommitment to a particular policy is not possible.

10. Hirshleifer and Thakor (1996) analyze a model in which the external market (takeovers) serves to discipline management as well as the board.

11. A detailed discussion of how SEC regulations have significantly contributed to the costs of proxy contests is to be found in Pound (1991). These costs comprise legal costs (which for control contests can be as high as 1.5 to 3.5 million dollars), the cost of obtaining the shareholder list and establishing direct contact with the shareholders, and advertisement costs. It has been argued that the high costs associated with a proxy challenge have been an important reason for their apparent lack of popularity in the post-1960 period (see Pound, 1992, p. 14).

12. In this regard, see footnote 8 . 
their information is acquired only after the dissident shareholder launches a tender offer or a proxy contest. The notion is that institutional investors, with a large portfolio of investments, find it too costly to monitor each individual firm. ${ }^{13}$ Once they are alerted by the action of a dissident shareholder, however, they utilize their staff of research analysts and draw upon their information sources to analyze the merits of the alternative policy being proposed. Among their sources of information is the incumbent management, which can be approached, and is usually more than willing, to disclose information in an effort to gain the support of institutional investors, particularly in proxy contests. ${ }^{14}$ Despite the information uncovered by the dissident shareholder, it seems reasonable that his information may not always dominate that of institutional investors in aggregate..$^{15}$ The institutional investors may also, on occasion, have better information about market conditions, potential competitors, pending legislation, and regulatory issues such as antitrust than the dissident shareholder. Dismal performance under current management may also prompt a relatively uninformed dissident (who possibly has high opportunity cost of monitoring or lacks firm- or industry-specific expertise) to propose a "reasonable alternative policy" - thereby attracting scrutiny by institutional investors and, possibly, their support if they find the alternative more attractive than current policy. ${ }^{16}$

Based on the discussion above, our assumption is that the information available to institutional investors is noisier than that available to an informed $L$. It is, however, less noisy than that available to an

13. For instance, according to a story on the role of large institutions in monitoring companies (Wall Street Journal, May 24, 1993), "The \$75 bn. CALPERS targets only 12 companies at a time and may cut back to 10 because of limited staff time."

14. Institutional investors are often actively lobbied by management and dissidents. Our view is that institutional investors interpret the information from these and other sources in arriving at their voting decisions. An example is the active lobbying of institutional investors in the 1996 Chrysler proxy initiated by Kerkorian. In the 1990 Lockheed proxy the dissident shareholder (Mr. Simmons) and the Lockheed chairman took their cases "to scores of institutions in more than a dozen cities, trying to convince them why a particular team is best suited to lead the aerospace giant" (Wall Street Journal, March $27,1990)$. Management and dissidents also use the media and proxy statements to publicize and build support for their positions.

15. For example, if all institutional investors have negative information about the proposed change, their aggregate information may be of high enough quality that a less than perfectly informed dissident would defer to their decision. A proxy contest may enable such information to be reflected in the outcome. Also, see footnote 17.

16. Sridharan and Reinganum (1995) find that firms with poor financial performance are more likely to be subject to proxy contests than to tender offers-a finding that is consistent in our model with the view that dissidents may use the proxy process to invite the scrutiny of institutional investors and rely on their information to implement a better policy. 
uninformed $L$. Hence, depending on the type of information obtained by $L$, the quality of his information may be more or less reliable than that of the institutional investors. ${ }^{17}$ It follows, therefore, that the voting behavior of institutional investors will be affected not only by their own information but also by their beliefs about the quality of the dissident's information. Formally we will assume that the institutional investors privately observe a signal $t$ that can take values $t^{+}$and $t^{-}$such that

$\operatorname{Pr}\left[t^{+} \mid z>0\right]=\operatorname{Pr}\left[t^{-} \mid z<0\right]=\pi \geq \frac{1}{2}$.

The institutional investors' strategy in a tender offer or a proxy challenge may depend on the signal that they receive (i.e., whether $t^{+}$or $t^{-}$) and its quality $\pi$. Note that if $\pi=1$, their signal tells them for sure in which interval $z$ lies, while if $\pi=\frac{1}{2}$, the signal is completely uninformative. ${ }^{18}$

To simplify the analysis, we take there to be only one institutional investor. By assumption, this investor is not pivotal in the tender offer if the fraction of the shares asked for is less than $\bar{\omega}$, since the dispersed shareholders own more than 50 percent of the shares. However, we assume that in the proxy contest the institutional investor's vote completely determines the outcome. For this, two assumptions are necessary: (a) the atomistic shareholders either do not vote or (since they are uninformed) vote randomly to largely cancel each other out, ${ }^{19}$ and (b) the institutional investor owns more than $|\alpha-\gamma|$ shares.

The assumption of only one institutional investor is obviously a far cry from reality, and some discussion of its significance for the analysis is called for. In fact, this assumption is not crucial for most of our conclusions. For instance, consider a scenario with several institutional investors, each of them observing a private informative signal

17. The reason we need the quality of information with $L$ not to dominate that of the institutional investors is that otherwise, there would not be any rational basis for the latter to ever oppose $L$, absent any benefits of control to the dissident in the model. A model in which there may be random benefits of control for the dissident but where the dissident is always better informed than the institutions will preserve many (but not all) of the features of the analysis. We do not deny that such benefits of control may occasionally motivate proxy contests; however, since many of the successful proxy contests result in divestitures and/or liquidations, we find it more natural to assume that the benefits of control reside exclusively with current management.

18. The probability $\operatorname{Pr}\left[t^{+} \mid z\right]$ as a function of $z$ in equation (1) is a step function, which jumps from a value $1-\pi$ that is less than $\frac{1}{2}$ to a value $\pi$ greater than $\frac{1}{2}$ as $z$ goes from less than zero to greater than zero (assuming there is no atom at $z=0$, the specification at $z=0$ does not matter). More generally, one would have a smooth increasing function with a value of $\frac{1}{2}$ at zero, values less than $\frac{1}{2}$ for $z<0$, and values greater than $\frac{1}{2}$ for $z>0$.

19. This is consistent with rational voting behavior, since atomistic shareholders do not expect to be pivotal and to affect the outcome of the proxy contest. 
of the type described above (of quality $\pi^{\prime}>\frac{1}{2}$ ). If a voting equilibrium exists in which they vote on the basis of their information (which could be different for any two such investors), then our analysis will go through completely if we reinterpret the probability $\pi$ in (1) as the probability that the proxy outcome is "yes" given that $z>0$ or "no" given $z<0 .{ }^{20}$

We now state a result regarding the voting behavior of the (single) institutional investor (henceforth denoted $N$ ). We say that $N$ votes with $L$ if he supports $L$ irrespective of his own private signal. We say $N$ votes on the basis of his own information if he opposes $L$ if and only if he observes $t^{-}$. Also, let $Z_{P}$ denote the set of $z$ for which an informed $L$ will go for a proxy contest.

\section{PROPOSITION 1:}

(a) If, in equilibrium, L participates in the proxy only when he is informed, then $N$ votes with L in a proxy. (b) If both the informed and the uninformed $L$ participate in the proxy, then $N$ votes on the basis of his own information if

$$
\begin{aligned}
-\frac{1}{2}(1-\mu)(2 \pi-1) E[z \mid z>0] & \\
& +\mu(1-\pi) \operatorname{Pr}\left[z \in Z_{P}\right] E\left[z \mid z \in Z_{P}\right]<0,
\end{aligned}
$$

and he votes with $L$ otherwise.

Proof. See the Appendix.

The intuition behind the proposition is straightforward. If, in equilibrium, only informed types of $L$ initiate proxy contests, the institutional investor will vote with $L$, given $L$ 's superior information. When both informed and uninformed $L$ types initiate proxy contests, however, N's voting strategy will depend on the proportion of uninformed $L$ types initiating proxies in equilibrium and the relative quality of his own information. Note that for $\mu=1$ and/or $\pi=$ $\frac{1}{2}$, the 1.h.s. of (2) is positive, while for $\mu=0$ and/or $\pi=1$, it is negative. A high enough ex ante probability of an informed $L$ or very poor quality of his own information will cause the institutional

20. The conditions under which such an equilibrium may exist or fail to exist were discussed in an earlier version of the paper available from the authors. These conditions are analogous to those given in Proposition 1. If only an informed $L$ participates in a proxy, then it is a dominant strategy for any institutional shareholder to vote with $L$, irrespective of his own information. On the other hand, if uninformed $L$ 's also participate, and there is a high enough proportion of such $L$ 's, then given that every other investor is voting on the basis of his information, it is optimal for a given institutional investor to do so, i.e., there is an equilibrium in which each institutional investor votes on the basis of his information. 
investor to vote with $L$; on the other hand, if his own information is of high quality or the probability of an informed $L$ is small, he will tend to rely on his own information.

\subsection{The SHARE-TENDERING Decision}

Proposition 1 was concerned with the behavior of the institutional investor in a proxy contest; the following proposition characterizes the share-tendering decision of both the institutional and atomistic shareholders in a tender offer.

Proposition 2: Suppose that, in equilibrium, only informed L's make a tender offer. Also suppose that the equilibrium is such that there exists a $z$ $>0$, say $z_{m}$, such that all informed L's who draw $z \geq z_{m}$ make a tender offer for a fraction $\frac{1}{2}-\alpha$ of the shares. Then any successful tender offer bid $b(\alpha)$ must satisfy

$b(\alpha) \geq q+E\left[z \mid z \geq z_{m}\right]$.

Proof. Note that for the institutional investor $N$, the fact that a tender offer has been made by $L$ conveys more information (i.e., $z$ belongs to $\left[z_{m}, \bar{z}\right]$ for sure) than his own informative signal-and so the latter will not affect his share tendering decision. Hence, for any passive shareholder, given that others are tendering and the tender offer will be successful, it is optimal not to tender if condition (3) does not hold. This means that for the tender offer to succeed, (3) must hold.

We shall assume that when the shareholders are indifferent between tendering and not tendering, they will tender. ${ }^{21}$ In view of this, the following is immediate:

COROLLARY 1: If the equilibrium has the features described in Proposition 2 , then any bid that satisfies condition (3) succeeds with probability one.

\section{The Choice between Proxies AND Tender OFFERS}

In this section, we consider L's choice between the two alternative methods of corporate control. To begin with, we state a lemma that is helpful

21. Hirshleifer and Titman (1990) allow shareholders to follow a randomization strategy and derive the equilibrium probability with which bids must be rejected for the bids to be fully revealing. This approach has the merit of being consistent with the observed phenomenon of bids being rejected with some probability. While it is possible to extend our analysis in this direction, we do not pursue it here. See also Chowdhry and Jegadeesh (1994). 


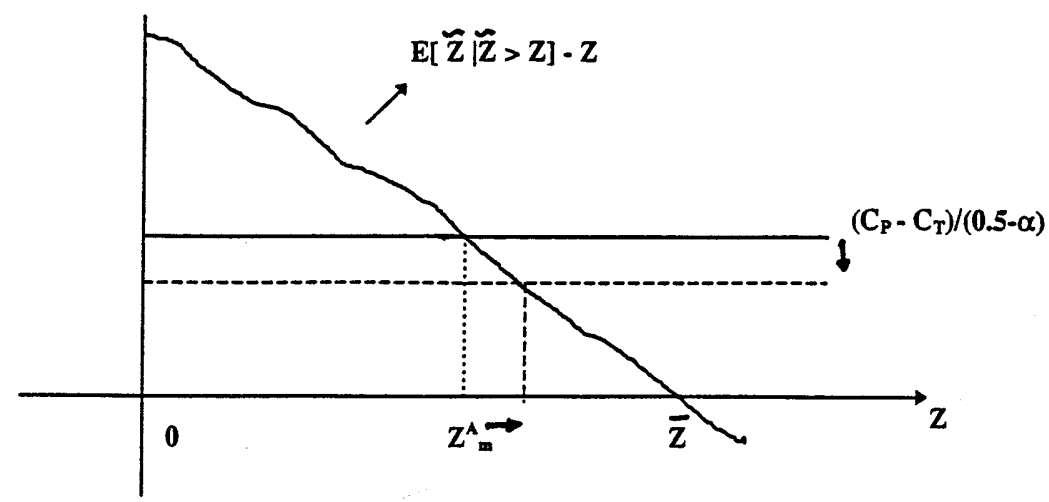

FIGURE 1. COMPARATIVE STATICS ON $z_{m}^{\mathrm{A}}$.

for the statement of our results and some of the comparative statics. The straightforward proof is omitted. ${ }^{22}$

LemMA 1: Given assumption $A 1$, for $k \leq 1, k E[\tilde{z} \mid \tilde{z} \geq z]-z$ is monotonically decreasing in $z$.

In what follows, we characterize two equilibria, one in which the institutional investor defers to the information of the dissident and always votes with $L$, and the other in which he votes on the basis of his own information. We label these, respectively, type $A$ and type $B$ equilibria.

\subsection{CHARACTERIZATION OF TYPE A EQUILIBRIA}

Let us define $z_{m}^{\mathrm{A}}$ as the unique $z$ (if it exists) which satisfies

$E[\tilde{z} \mid \tilde{z} \geq z]-z=\frac{c_{P}-c_{T}}{\frac{1}{2}-\alpha}$

and let $z_{l}^{\mathrm{A}}$ be defined as

$z_{l}^{\mathrm{A}}=\frac{c_{P}}{\alpha}$.

Notice that by virtue of $\mathrm{A} 2$, it is immediate that $z_{l}^{\mathrm{A}}>0$ and $z_{m}^{\mathrm{A}}<\bar{z}$ (see Fig. 1). We make the following assumption: 
A3: $\quad(0<) z_{l}^{\mathrm{A}}<z_{m}^{\mathrm{A}}(<\bar{z})$.

To see that there are parameter values for which A3 will be satisfied, it is enough to note that (1) $c_{P}-c_{T}>0$ implies $z_{m}^{\mathrm{A}}<\bar{z}$, (2) $z_{l}^{\mathrm{A}}$ is positively related to $c_{P}$ and tends to zero as $c_{P}$ tends to zero, and (3) $z_{m}^{\mathrm{A}}$ is negatively related to $c_{p}-c_{T}$ and tends to $\bar{z}$ as $c_{T}$ and $c_{P}$ both tend to zero. (See Fig. 1.) As an example, suppose $z$ is uniform over [ -1 , $1], c_{P}=0.05, c_{T}=0$, and $\alpha=0.1$. Then we have $z_{l}^{\mathrm{A}}=0.5$ and $z_{m}^{\mathrm{A}}=$ 0.75 .

The significance of $z_{l}^{\mathrm{A}}$ and $z_{m}^{\mathrm{A}}$ is as follows. If the equilibrium is such that $N$ votes with $L$, then $L$ wins the proxy contest with probability 1 . Hence, the expected payoff to an informed $L$ from a proxy contest is $\alpha z-c_{P}$. Here $z_{l}^{A}$ is the lowest value of $z$ for which this is nonnegative, i.e., the lowest $z$ for which an informed $L$ will participate in the proxy, given that $N$ will vote with $L$.

To understand $z_{m}^{\mathrm{A}}$, note that if $z$ is such that $L$ will go for a tender offer if and only if $L$ is informed and draws $z \geq z$, then the lowest price at which the tender offer will be successful is $b=q+E[\tilde{z} \mid \tilde{z} \geq z]$. The gain to $L$ from a tender offer is then

$$
\begin{aligned}
0.5(q+z)-(0.5-\alpha) b-\alpha q- & c_{T} \\
& =0.5 z-(0.5-\alpha) E[\tilde{z} \mid \tilde{z} \geq z]-c_{T} .
\end{aligned}
$$

The gain to $L$ for the same $z$ from a proxy contest that he will win for sure is $\alpha z-c_{P}$.

It is easily checked that for $z=z_{m}^{\mathrm{A}}$, the gains from a tender offer and a proxy challenge are the same, i.e., $z_{m}^{\mathrm{A}}$ is the value of $z$ for which $L$ is indifferent between a tender offer and a proxy challenge if, in equilibrium, $L$ goes for a tender offer if and only if $z \geq z_{m}^{\mathrm{A}}$.

We are now ready to characterize one equilibrium of interest.

Proposition 3: Under assumptions $A 1-A 3$, there exists a (semipooling) equilibrium in which:

(i) Informed $L$ types bid for a fraction $0.5-\alpha$ of the shares at a price $b^{*}(\alpha)$ $=q+E\left[\tilde{z} \mid \tilde{z} \geq z_{m}^{\mathrm{A}}\right]$ if $z>z_{m}^{\mathrm{A}}$, and go for a proxy challenge if $\tilde{z} \in$ $\left[z_{l}^{\mathrm{A}}, z_{m}^{\mathrm{A}}\right)$.

(ii) Uninformed L types, and informed L types with $z<z_{l}^{\mathrm{A}}$, stay out.

(iii) Shareholders tender their shares if a tender offer is made, and $N$ votes with $L$ if a proxy challenge is initiated by $L$.

Further, this is the only semipooling equilibrium in which $N$ votes with $L$ that is consistent with the Grossman-Perry refinement.

Proof. See the Appendix. 
The equilibrium described in Proposition 3 is a semipooling equilibrium in the sense that for all $z \in\left[z_{l}^{\mathrm{A}}, z_{m}^{\mathrm{A}}\right), L$ initiates a proxy challenge, while for all $z>z_{m}^{\mathrm{A}}, L$ makes a tender offer. The reason why the high- $z$ types go for a tender offer whereas the lower- $z$ types prefer a proxy contest is as follows. Since both tender offers and proxy contests succeed with probability 1 , the choice of the takeover mechanism reflects the respective costs. For a proxy contest, the cost is $c_{P}$; however, for a tender offer, the costs involve $c_{T}$ plus the adverse-selection costs. The latter arise because-as in Shleifer and Vishny (1986) - the bid price reflects pooling across all the types that bid [see equation (3)], so that the low types in the pool always pay a premium over the true value. Since $c_{T}<c_{P}$ and for the highest type $\bar{z}$ the adverse-selection cost is absent, the highest type will always go for a tender offer. By continuity, there will an interval of the highest types that do so, until the adverse-selection costs become too high.

The voting behavior of the institutional shareholders in the equilibrium described in Proposition 3 is an example of an "informational cascade" in the sense of Bikhchandani et al. (1992). ${ }^{23}$ We shall call such an equilibrium a semipooling equilibrium of type A. Under our assumptions, it is nondegenerate in that both tender offers and proxy contests occur with nonzero probability. If A2 is violated, tender offers will not be observed and we shall have a pure pooling equilibrium in which $L$ chooses a proxy contest for $z \geq z_{l}^{\mathrm{A}}{ }^{24}$ It is easy to see that a pure pooling equilibrium in which only tender offers are observed is possible if $c_{P}$ is sufficiently high.

As noted, one feature of this equilibrium is that a proxy challenge succeeds with probability 1 . Since the observed success rate in proxy challenges is far from being 100 percent, this may not seem very appealing. One possible reconciliation is to assume that institutions exhibit some bias towards management in voting behavior, and that proxy challenges are defeated with probability $1-\beta$, irrespective of the institutional investor's information. However, this is not the only way to reconcile theory and practice. As we discuss next, there is another equilibrium (type B) in which the institutional investor votes according to his information and proxy challenges do get defeated some of the time (even without management bias). We shall argue later that the observational equivalence of a type A equilibrium with bias and a type B equi-

23. An informational cascade occurs when it is optimal for an individual who observes the actions of those ahead of him to follow the latter's behavior without regard to his own information.

24. However, if we introduce promanagement bias in proxy voting, tender offers would be observed even for some $c_{P}<c_{T}$. See Sections 6 and 7 . 
librium (with or without bias) can lead to unwarranted conclusions from the observed failure rate of proxy challenges.

\subsection{CHARACTERIZATION OF TYPE B EQUILIBRIA}

For $N$ to vote on the basis of his own information, condition (2) has to be satisfied. Moreover, it must be optimal for an uninformed $L$ to participate in the proxy contest. This requires the expected gain for an uninformed $L$ from a proxy challenge, given that $N$ is voting on the basis of his own information, to be positive, i.e.,

$$
\begin{aligned}
\alpha\left\{\operatorname{Pr}[z>0] \operatorname{Pr}\left[t^{+} \mid z>0\right] E[z \mid z>0]\right. \\
\left.+\operatorname{Pr}[z<0] \operatorname{Pr}\left[t^{+} \mid z<0\right] E[z \mid z<0]\right\}-c_{P} \geq 0 .
\end{aligned}
$$

By virtue of (1) and the assumption that $E[z \mid z>0]=-E[z \mid z<0]$, this reduces to

$\frac{1}{2} \alpha(2 \pi-1) E[z \mid z>0]-c_{P} \geq 0$.

It is evident that the condition holds for $c_{P}$ (and $c_{T}$-in view of A2) small enough, and for $\pi>\frac{1}{2}$.

Let $k=(0.5-\alpha) /(0.5-\alpha \pi)$. Notice that $k<1$. Appealing to Lemma 1 , let us define $z_{m}^{\mathrm{B}}$ to be the unique $z$ (if it exists at all) such that

$k E\left[\tilde{z} \mid \tilde{z} \geq z_{m}^{\mathrm{B}}\right]-z_{m}^{\mathrm{B}}=\frac{\mathcal{c}_{P}-c_{T}}{0.5-\alpha \pi}$.

Also, define $z_{l}^{B}$ as

$z_{l}^{\mathrm{B}}=\frac{c_{P}}{\alpha \pi}$.

As before, it is immediate from A2 that $z_{l}^{\mathrm{B}}>0$ and $z_{m}^{\mathrm{B}}<\bar{z}$ (see Fig. 2). We shall make the following assumption:

A4: $\quad(0<) z_{l}^{\mathrm{B}}<z_{m}^{\mathrm{B}}(<\bar{z})$.

Again, it is easily seen that there are parameter values for which the assumption is satisfied, since $z_{l}^{\mathrm{B}}$ tends to zero as $c_{P}$ tends to zero, and $z_{m}^{\mathrm{B}}$ tends to an upper bound as $c_{P}$ and $c_{T}$ both tend to zero. As an example, suppose $z$ is uniform over $[-1,1], c_{P}=0.05, c_{T}=0, \alpha=$ 0.1 , and $\pi=0.9$. Then we have $z_{l}^{\mathrm{B}}=0.555$ and $z_{m}^{\mathrm{B}}=0.71$.

The significance of $z_{m}^{\mathrm{B}}$ and $z_{l}^{\mathrm{B}}$ is similar to that of $z_{m}^{\mathrm{A}}$ and $z_{l}^{\mathrm{A}}$, respectively. If the equilibrium is such that $N$ votes on the basis of his own information, then an informed $L$ wins the proxy with probability $\pi$. Hence, the expected payoff to an informed $L$ from a proxy is 


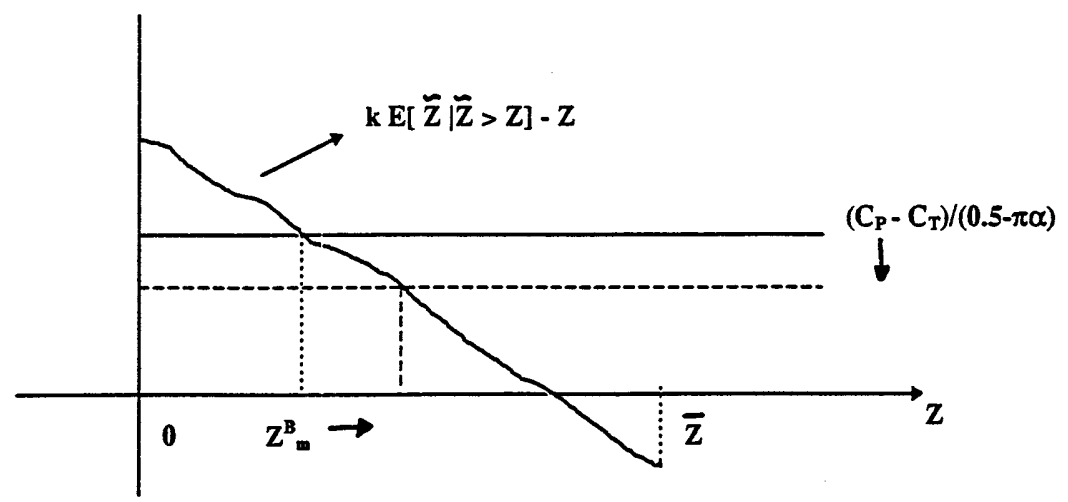

FIGURE 2. COMPARATIVE STATICS ON $z_{m}^{\mathrm{B}}$.

$\alpha \pi z-c_{P}$. Here $z_{l}^{B}$ is the lowest value of $z$ for which this is nonnegative, i.e., the lowest $z$ for which an informed $L$ will initiate the proxy, given that $N$ will vote on the basis of his own information.

To understand $z_{m}^{\mathrm{B}}$, note that if there is a $z$ such that $L$ will go for a tender offer if and only if he is informed and draws $\tilde{z} \geq z$, then the lowest price at which the tender offer will be successful is $b=q+$ $E[\tilde{z} \mid \tilde{z} \geq z]$. The gain to $L$ (given that $z$ is obtained) from a tender offer is, as before, equal to $0.5 z-(0.5-\alpha) E[\tilde{z} \mid \tilde{z} \geq z]-c_{T}$. The gain to $L$ for the same $z$ from a proxy which he will win with probability $\pi$ is $\alpha \pi z-c_{P}$. (See Fig. 2.) It is easily checked that for $z=z_{m}^{\mathrm{B}}$, the gain from a tender offer and a proxy challenge are the same, i.e., $z_{m}^{\mathrm{B}}$ is the value of $z$ at which $L$ is indifferent between a tender offer and a proxy challenge if, in equilibrium, $L$ makes a tender offer when $z \geq z_{m}^{\mathrm{B}}$. We are now ready to characterize a second type of equilibrium:

Proposition 4: Under assumptions $A 1, A 2$, and $A 4$, if conditions (2) and (6) hold, there exists a semipooling equilibrium in which:

(i) Informed $L$ types bid for a fraction $0.5-\alpha$ of the shares at a price $b^{*}(\alpha)$ $=q+E\left[\tilde{z} \mid \tilde{z} \geq z_{m}^{\mathrm{B}}\right]$ if $z>z_{m}^{\mathrm{B}}$, and go for a proxy challenge if $z \in$ $\left[z_{l}^{\mathrm{B}}, z_{m}^{\mathrm{B}}\right)$.

(ii) Informed L types with $z<z_{l}^{\mathrm{B}}$ stay out.

(iii) Uninformed L types go for a proxy challenge.

(iv) Shareholders tender their shares if a tender offer is made, and $N$ votes on the basis of his own information in a proxy contest.

Further, this is the only semipooling equilibrium in which $N$ votes on the basis of his own information that is consistent with the Grossman-Perry refinement. 
Proof. The proof follows that of Proposition 3 very closely and is omitted.

An interesting aspect of type B equilibria is that while it is unprofitable for an informed $L$ with low but positive $z$ to initiate a proxy (i.e., all $z \in\left[0, z_{l}^{B}\right)$ ), it is still profitable for an uninformed $L$ with $E[z]=0$ to do so. The explanation for this is that the uninformed $L$, given that he utilizes the filter of the institutional investors, can benefit from the potentially large upside (if $z>0$ ) but be protected from the downside (if $z<0$ ) if the latter are well informed. This makes it profitable for an uninformed $L$ to initiate a proxy, though not for an informed $L$ with low positive $z$. This is also obviously a source of value for the firm: given that the institutional investor is informed $(\pi>0.5)$, a proxy does more good than harm when the potential for value improvement exists ex ante. Hence, when the proportion of uninformed Ls is sufficiently high, one would expect type B equilibrium to be more desirable for firm value. This issue will be taken up in detail in Section 7.

It has been argued [most notably by Pound $(1988,1992)]$ that tender offers will be initiated by a dissident only when he is relatively confident in his ex post ability to increase share value. Proxy challenges, on the other hand, may be initiated by an insurgent shareholder who is "seeking personal satisfaction, or may be no more than a wealthy crank." The type B equilibrium is reminiscent of this type of characterization. Tender offers are initiated only by informed $L$ 's with high potential for value improvement. Proxy challenges, on the other hand, may be initiated by informed L's with low potential for value improvement, or relatively uninformed dissidents. The latter-given that they have their own stakes in the firm-will rely on the efficiency of the proxy process itself (i.e., the information of the institutional shareholders) to compensate them for the costs of conducting a proxy challenge. In Section 4, we shall consider some additional implications of this type of characterization..$^{25}$

Two other important features of type B equilibria are that, for $\pi$ $<1$, (1) proxies are defeated with positive probability, even in the absence of bias, and (2) the ex post performance of the firm after a successful proxy challenge (by an uninformed $L$ ) could be worse than 
under current management. This last feature is consistent with evidence in Mulherin and Poulsen (1995). ${ }^{26}$

\section{ANNOUNCEMENT EFFECTS}

Stock price reactions following announcements of tender offers are, on average, more favorable than those following announcements of proxy initiatives. DeAngelo and DeAngelo (1989) study 60 proxy contests for board seats of exchange-listed firms during 1978-1985. They find that the average 2-day abnormal stock return around the first report of dissident activity is 4.85 percent, while the average 40 -day cumulative abnormal return is 18.76 percent. In comparison with these findings, stock price increases following announcements of tender offers are typically larger. Jarrell et al. (1988), citing a study by the Office of the Chief Economist of the SEC, report that, for a sample of 225 successful tender offers during 1981-1984, the average premium to shareholders was 53.2 percent. ${ }^{27}$ Jarrell and Poulsen (1987) report that in their sample of 663 successful tender offers between 1962 and 1985, the figures were 19 percent in the 1960s, 35 percent in the 1970s, and 30 percent for 1980-1985.

Our model is consistent with these findings. Given that in either type of equilibrium the dissident shareholder chooses to make a tender offer when the $z$ is high, it is intuitive that tender-offer announcements will be associated with a more positive price reaction than proxy announcements. This is confirmed in the following:

Proposition 5: In both types of equilibria, the price reaction following the announcement of a tender offer is greater than that of a proxy challenge. The former is always positive, and the latter is positive for $\rho$ sufficiently small.

Proof. See the Appendix.

It should also be noted that instances in which dissidents lose proxy contests tend to be associated with a decrease in firm stock price. It has been suggested that this is reflective of inefficiencies in the proxy process such as promanagement bias on the part of the institutional investors. However, it is clear that such price reactions are perfectly

26. They report that a substantial fraction of firms with proxy contests experience wealth losses in the year following the successful resolution of the contest (e.g., when the dissident wins board seats). The ex post performance is, however, significantly better when the proxy contest results in senior management being replaced.

27. The premium is calculated by comparing the price paid by the bidder with the price at which the stock was trading one month before the offer. 
consistent with our model in which promanagement bias is absent. Proxy challenges are defeated only in a type B equilibrium and reflect unfavorable information on the part of the institutional shareholder. This implies that proxy defeats should lead to a drop in expected firm value, since, prior to resolution of the proxy contest, there is some probability with which the proxy is expected to succeed and lead to a beneficial change in firm policy.

We now state some comparative static results:

Proposition 6: In a type A equilibrium:

1(i) The probability of a tender offer is increasing in $c_{P}$, decreasing in $c_{T}$, and increasing in $\alpha$.

1(ii) The magnitude of the price reaction following a tender-offer announcement is decreasing in $c_{P}$ for $\rho$ sufficiently small, increasing in $c_{T}$, and decreasing in $\alpha$.

2(i) The probability of a proxy challenge is decreasing in $c_{P}$, increasing in $c_{T}$, but ambiguous w.r.t. change in $\alpha$.

2(ii) The price reaction following the announcement of a proxy challenge is ambiguous w.r.t. a change in $c_{P}$, increasing in $c_{T}$, and decreasing in $\alpha$.

Proof. See the Appendix.

For type $\mathrm{B}$ equilibria, the results for $c_{P}, c_{T}$, and $\alpha$ are completely analogous to Proposition 6 for type A equilibria. An increase in $\pi$ can be shown to reduce the probability of a tender offer and increase the magnitude of the price reaction following a tender-offer announcement. It increases the probability of a proxy contest, and has an ambiguous effect on the magnitude of the stock price reaction following a proxy announcement.

Existing empirical evidence, where available, is consistent with these predictions. Jarrell and Bradley (1980) find that takeover premia in tender offers increased after the Williams Act of 1968, which is regarded as having increased takeover costs. Sridharan and Reinganum (1995) find evidence that the probability of proxy contests increases as the firm becomes more insider-dominated. This is consistent with the view that in these situations, institutions are more vigilant and better informed (higher $\pi$ ), leading to higher probability of proxy contests.

\section{EFFEct of PARAMETER Changes on Firm VAlue}

In this section, our objective is to evaluate the effect of changes in model parameters, say on account of policy changes, on firm value. From this standpoint, type B equilibria are more interesting, since policy changes 
involve substitutions on the margin between tender offers and proxy contests, and the quality of information with the institutional investors thus becomes very important. This is not an issue in type A equilibria, since the institutional investors do not vote on the basis of their own information.

Proposition 7: In a type A equilibrium, firm value is increasing in $\alpha$, decreasing in $c_{P}$, and unaffected by $c_{T}$.

Proof. See the Appendix.

Proposition 8: In a type B equilibrium:

1. An increase in the costs of a proxy lowers the success rate of the proxy, but has an ambiguous effect on firm value. For $\pi$ sufficiently close to 1, firm value decreases as $c_{P}$ increases.

2. An increase in tender-offer costs $c_{T}$, ceteris paribus, increases the success rate of the proxy, but lowers firm value.

3. An increase in $\alpha$ increases firm value, but has an ambiguous effect on the success rate of the proxy.

4. For $\pi$ sufficiently close to 1 , an increase in $\pi$ increases firm value. An increase in $\pi$ always increases the success rate of proxies.

Proof. See the Appendix.

Part 1 of Proposition 8 indicates the interesting possibility that if the proxy process is not very efficient (i.e., $\pi$ is low), lowering the costs of conducting a proxy contest may be an inappropriate policy response. Increasing the cost of a proxy contest may be beneficial because this would encourage more tender offers at the expense of proxy challenges, while the fact that fewer informed $L$ 's initiate proxy challenges will not be costly if $\pi$ is low. Part 2 differs from Proposition 7 in that in a type B equilibrium, greater reliance on proxy contests at the expense of tender offers means that institutional investors determine the proxy outcome, and so a (perfectly) informed $L$ will be defeated some of the time (this does not happen with tender offers). The same reasoning underlies part 4-higher $\pi$ on the margin causes proxy contests to displace tender offers. Unless $\pi$ is high, it is possible that an increase in $\pi$ can lower firm value.

\section{Promanagement bias and Voting Behavior}

An important issue in the literature on proxy voting has been that of promanagement bias in the proxy-voting behavior of institutional investors. Several authors have argued that institutional investors, either to 
protect their business relationship with companies or for other reasons, routinely vote in favor of management. The Department of Labor's recent reiterations of ERISA's fiduciary rules essentially require whoever has voting authority (either the plan fiduciary or the investment manager) to use a formal written policy to avoid conflict of interest. Thus, implicitly at least, the potential for promanagement bias seems to have been taken for granted. ${ }^{28}$

To address some policy issues, it is useful to incorporate the possibility of such bias into our analysis. We do this by assuming that with a probability $1-\beta$, the institutional investor is perceived to vote in favor of management, irrespective of information. ${ }^{29}$ In a type A equilibrium this implies that the proxy challenge succeeds with probability $\beta$.

Proposition 9: In type A equilibrium, the success rate and frequency of proxy contests are decreasing in the degree of management bias, $1-\beta$. For $\beta$ sufficiently close to 1 , firm value is also decreasing in the degree of management bias.

Proof. See the Appendix.

The part of Proposition 9 that may be somewhat nonintuitive is that it requires $\beta$ to be sufficiently larger for the firm value to be decreasing in the degree of management bias. In fact, it can be easily checked that firm value may not be increasing in $\beta .^{30}$ The intuition here is that greater management bias reduces the benefits from proxies and causes tender offers to replace proxy contests on the margin. This increases firm value when the loss from the lower efficiency of proxy contests due to the lower $\beta$ is small, i.e., when proxies are not used very frequently.

For type B equilibrium, analogous results are obtained. We do

28. Brickley et al. (1988) find that, for antitakeover proposals, while institutional shareholders as a group appear "vigilant" (vote more actively than nonblockholders and oppose management when the proposals seem to harm shareholders), pressure-sensitive institutional investors such as banks and insurance companies tend to favor management. In the only study to date on voter-level data, Van Nuys (1993) finds that for the Honeywell proxy solicitation case in 1989, more than half of the 72 largest institutional investors, holding 41.5 percent of the shares, voted in favor of the dissidents. Significantly, however, while banks and insurance companies tended to support management, their voting behavior did not appear to depend on whether or not they had business ties to the firm.

29. For example, the management might control a block of votes of random size. If the size of this block exceeds the total number of shares with the dissident and those institutional investors not biased towards management, the outcome of the proxy is in favor of management. Let $1-\beta$ denote the probability of this event.

30. In the working paper Dasgupta and Nanda (1995), we provide an example in which for $\beta$ small, firm value is decreasing in $\beta$. 
not repeat the analysis here. We next discuss policy issues related to voting bias and fiduciary responsibility.

\section{Multiple Equilibria, Management Bias, AND FIDUCIARY RESPONSIBILITY}

We have so far discussed equilibria A and B separately. It will be established below that there exist parameter values for which both equilibria are feasible. In this section we discuss the conditions under which one of these equilibria may dominate in terms of firm value maximization, when both can exist. We also discuss under what conditions one type of equilibrium may be expected to prevail rather than the other. An interesting issue that arises is whether, as a result of policy actions, a particular equilibrium may be eliminated.

We begin by characterizing conditions under which multiple equilibria can exist:

Proposition 10: So long as $A 1$ and $A 2$ hold, nondegenerate ${ }^{31}$ type $A$ equilibria exist for all parameter values for which nondegenerate type B equilibria exist, but not vice versa.

Proof. See the Appendix.

In equilibrium $B$ the proxy process is used by uninformed $L$ 's as a way to tap into the information of passive institutional shareholders. Intuitively one would therefore expect the benefits of the proxy process to be increasing in the relative quality of the institutional shareholder's information. In terms of model parameters a higher $\pi$ (quality of passive shareholder information) and $1-\mu$ (the fraction of uninformed $L$ 's) makes it more likely that the existence conditions for type B equilibrium are satisfied. When both equilibria can exist, we may also expect higher values of these parameters to be associated with a larger firm value under equilibrium $B$ than under equilibrium $A$. This intuition is formalized below:

Proposition 11(I): For any $\pi>\frac{1}{2}$ for which the uninformed L's participation constraint holds holds, define $\mu^{*}$ to be the critical value of $\mu$ such that condition (2) is satisfied for $\mu<\mu^{*}$. Then:

(a) There exists a value $\mu(\pi, \beta)$ of $\mu$, where $\mu(\pi, \beta) \leq \mu^{*}$, such that type $B$ equilibrium exists and dominates type A equilibrium iff $\mu<\mu(\pi, \beta)$.

31. By nondegenerate, we mean equilibria in which both tender offers and proxy challenges are used with positive probability. 
(b) $\mu(\pi, \beta) \rightarrow 1$ as $\pi \rightarrow 1$.

Proof. See the Appendix.

Part (a) indicates that, given any $\pi>\frac{1}{2}$, firm value is higher under type B equilibrium if the proportion of informed $L$ 's is sufficiently small. To understand why, we need to remind ourselves that in type B equilibrium, in contrast to type $\mathrm{A}$, the uninformed $L$ also initiates a proxy, and this is beneficial for firm value so long as $\pi>\frac{1}{2}$. Part (b) of the proposition is intuitive: it indicates that type B will dominate if $\pi$ is large enough.

The relative frequency with which tender offers and proxy contests are selected depends on the particular equilibrium that prevails. When both equilibria can exist, the occurrence of tender offers and proxy contests can be characterized as follows:

Proposition 11(II): For any set of parameter values for which both types of equilibria exist, tender offers are more frequent in type $B$ equilibria than in type $A$. There exists a value of $\mu$, say $\mu^{p}$, such that proxy contests are less frequent in type $B$ equilibrium than in type $A$ for $\mu \geq \mu^{p}$, but more frequent for $\mu<\mu^{p}$, provided that a type B equilibrium is viable at the particular value of $\mu$ being considered. ${ }^{32}$

Proof. See the Appendix.

That tender offers are used more frequently in an equilibrium in which the proxy process is more meaningful may appear counterintuitive. The reason is that, in a type B equilibrium, the perfectly informed large shareholder is defeated with some probability, and this encourages the use of tender offers. On the other hand, in a type B equilibrium, the participation of uninformed $L$ 's in the proxy is encouraged. If the proportion of uninformed L's is high, the frequency of proxies will be also higher in a type B equilibrium.

It may be interesting to speculate on whether or not there are particular firm characteristics that make one or the other equilibrium more likely to prevail. Notice that only type A equilibria are possible if either conditions (2) or (6) do not hold. This situation arises if (i) $\pi$ is low (possibly related to low and/or dispersed levels of institutional investor ownership in the firm), (ii) the potential for bias is high, due to the larger presence of pressure-sensitive institutional investors such as banks or insurance companies (Brickley et al., 1988), (iii) $\mu$ is high

32. Recall that for $\mu$ too large, condition (2) will not hold and type B will not be viable. 
(the dissident is a former insider, or has established reputation for successful takeovers), (iv) the dissident's stake $\alpha$ is low, and (v) the potential value improvement (i.e., $E[z \mid z>0]$ ) is low in relation to proxy costs $c_{P}$-which might be true of smaller firms. Since, by Proposition 10 , type A equilibria are possible whenever type B equilibria are, it is difficult to be specific as to when the latter will prevail. However, one particular factor that may favor the existence of type B equilibria is significant institutional ownership. In part this is because institutional investors may be expected to be better informed when their ownership stake is higher. Also, the expected liability of the institutional investors from potential lawsuits for breach of fiduciary responsibility may increase with their ownership stake in the firm, causing them to pursue a policy of informed voting. Knowing this, a dissident large shareholder may be motivated to initiate a proxy contest even when not highly informed.

The discussion above has identified conditions under which firm value is larger if one equilibrium rather than the other prevails, when both are possible. We now consider the possibility that as a consequence of policy actions by regulatory authorities or by changes to the firm's corporate charter, a particular equilibrium may be eliminated.

\subsection{ERISA AND FIDUCIARY RESPONSIBILITY}

The US Department of Labor (DOL) in recent years has repeatedly made fiduciaries of employment benefit plans under ERISA aware of their obligations concerning proxy voting. A possible consequence of such rules may be that institutions, in an effort to justify their voting practices, will vote proxies on the basis of their own information. However, as we argue below, this may not be desirable if the quality of the information with institutional investors is relatively poor. Even in the presence of significant management bias, the DOL policy could be harmful.

We show this by way of an example. Suppose that (6) does not hold: this means that even when the institutional investor is forced to vote on the basis of his own information and bias is eliminated ( $\beta=$ 1 ), the uninformed $L$ does not participate. Under such circumstances, the firm value is given by

$V^{\mathrm{DOL}}=q+\mu \rho\left(\pi \int_{z_{l}^{\mathrm{B}}}^{z_{m}^{\mathrm{B}}} z d F+\int_{z_{m}^{\mathrm{B}}}^{\bar{z}} z d F\right)$.

Notice now that since the uninformed $L$ cannot participate when $\beta=$ 1 [(6) does not hold], he cannot participate when there is bias. Thus, 
only type A equilibrium would prevail before the change in policy. The firm value before the policy change is given by

$$
V^{\mathrm{A}}(\beta)=q+\mu \rho\left(\beta \int_{z_{l}^{\mathrm{A}}(\beta)}^{z_{m}^{\mathrm{A}}(\beta)} z d F+\int_{z_{m}^{\mathrm{A}}(\beta)}^{\bar{z}} z d F\right)
$$

Now suppose $\beta=\pi$. Then it is readily checked that $z_{l}^{\mathrm{A}}(\beta)=z_{l}^{\mathrm{B}}(\beta=$ $1)$ and $z_{m}^{\mathrm{A}}(\beta)=z_{m}^{\mathrm{B}}(\beta=1)$, and $V^{\mathrm{A}}(\beta)=V^{\mathrm{DOL}} \cdot{ }^{33}$ For all $\beta>\pi$, therefore, $V^{\mathrm{A}}(\beta)>V^{\mathrm{DOL}}$. In other words, if the efficiency of the proxy process (measured by the quality of information possessed by the institutional investors) is not sufficiently high, forcing institutional investors to vote on the basis of their information (and eliminating bias) may not improve upon a process in which there is some bias. In this regard, policies that tend to improve the quality of institutional shareholder information-for example, the recent decision by the SEC to relax its restrictions on shareholder communications (and solicitations) - could prove beneficial.

We summarize the above discussion in the following:

Proposition 12: Irrespective of whether or not management bias is present, a policy that obliges the institutional investors to vote on the basis of their information may decrease firm value.

\subsection{INSTITUTIONAL OWNERSHIP AND PROXY CONTESTS}

Pound (1988) finds that firms with greater institutional ownership are less likely to experience proxy contests for control, ${ }^{34}$ and such challenges, when they do take place, are less likely to succeed. He attributes these findings to promanagement bias in proxy voting by institutions. Note, however, that these findings are also consistent with the discussion above to the effect that a type B equilibrium is more likely when institutional investors own larger stakes in a firm, since they have the incentive to be better informed and to pursue a policy of informed voting. ${ }^{35}$ Compared to a type A equilibrium, this would lead to lower

33. What this means is that type A equilibrium with bias $1-\beta$ is equivalent to type B equilibrium with $\pi=\beta$ in which the uninformed $L$ does not participate-in both cases, proxy challenges are successful with probability $\beta$. For expressions for $z_{m}^{\mathrm{A}}(\beta)$ and $z_{l}^{\mathrm{A}}(\beta)$, see the proof of Proposition 9.

34. As opposed to other types of proxy contests, such as antitakeover amendments. The idea here is that institutions tend to be more conservative and favor management when major policy changes are at issue.

35. An alternative argument would appeal to the notion of a "focal point" facilitating coordination among strategic players: the high level of institutional ownership allows coordination to a better equilibrium. 
success rate in proxy challenges for such firms (since the challenges are defeated some of the time in a type B equilibrium). By virtue of Proposition 11(ii), one would also observe a greater use of tender offers for control contests. Since tender offers and proxy contests are substitute mechanisms for control contests but not for other types of proxy initiatives, one would see lower use of proxy contests for control as a proportion of all proxy initiatives. These are exactly the same findings as in Pound (1988), but obviously, the implications for firm value are quite different. Pound associates these findings with management bias and lower firm value, whereas, under the alternative interpretation suggested here, the firm value may well be higher [see Proposition 11(i), part (b)].

\section{CONCLUDING REMARKS}

This paper has analyzed tender offers and proxy contests as alternative means of exercising corporate control. We have argued that though proxy contests may be more costly to organize than tender offers, they may allow a dissident to draw upon the information of other shareholders when his own information is poor. When the dissident is confident about the need to change corporate policy, he may be less willing to risk losing a proxy contest and may choose to make a tender offer instead. The predictions of the model are consistent with the empirical evidence on the announcement effects of proxy contests and tender offers on firm stock price. The model is extended to allow for promanagement bias in proxy voting by institutional investors, and the results shown to be robust to the existence of such bias.

A broad message of the paper is that certain policy recommendations as well as interpretations of empirical regularities in the literature appear dubious-once we explicitly recognize the substitutability between proxy contests and tender offers and consider the information of both dissidents and other shareholders. An instance is the indirect evidence of promanagement bias in voting by institutional investors that, we have argued, is consistent with unbiased voting on the part of institutions. Also, the fact that proxies are sometimes defeated, accompanied with a drop in firm stock price, is quite consistent with the absence of voting bias. Therefore, policies directed to counter such bias may be premature, in the absence of direct voting-level evidence. In any case, we have argued that even in the presence of voting bias, it is not obvious that requiring institutions to vote on the basis of their information is necessarily a good idea. Nor is it obvious that it is socially desirable to lower the costs of conducting proxies, given the substitutability between proxy contests and tender offers. 
There is scant empirical evidence on the nature of the substitutability between proxy contests and tender offers aside from Pound (1991, 1992), who identifies changes in the costs of conducting proxy contests that may have diminished their popularity relative to tender offers. We believe that our model provides a systematic framework in which to examine the historical evidence on the effect of changes in regulatory and other costs on the frequency and success rates of proxy contests and tender offers, changes in the announcement effects on stock prices, and the characteristics of dissidents and other shareholders. The model may also provide a useful framework in which to examine cross-sectional and cross-country differences in the manner in which control contests are initiated and resolved. Our hope is that this paper may play a role in stimulating such work in the future.

\section{APPENDIX}

Proof of Proposition 1. (a): If the uninformed $L$ does not participate in the proxy, then the announcement of a proxy is possible only if $z>$ 0 , since the expected gain from a proxy to an informed $L$ is $\alpha z \operatorname{Pr}[L$ wins proxy] $-c_{P}$, which is nonnegative only if $z>0$. Consequently, irrespective of his own information, $N$ must support $L$.

(b): Suppose $N$ observes $t^{-}$. We shall compute the expected improvement in firm value from supporting $L$ ( $N^{\prime}$ s gain is proportional to this). $N^{\prime}$ s information set consists of $t=t^{-}$and the fact that a proxy has been announced. Let $H$ denote the latter event. Then $H \equiv\left\{h_{1}, h_{2}\right\}$, where $h_{1}$ is the event that an uninformed $L$ makes the proxy challenge, and $h_{2}$ is the event that an informed $L$ makes it.

The expected improvement in firm value is

$$
\begin{aligned}
E\left[z \mid t^{-}, H\right]=\operatorname{Pr}\left[h_{1} \mid t^{-}\right] E\left[z \mid t^{-},\right. & \left.h_{1}\right] \\
& +\operatorname{Pr}\left[h_{2} \mid t^{-}\right] E\left[z \mid t^{-}, h_{2}\right] .
\end{aligned}
$$

It can be readily checked (using the fact that the unconditional probability of observing $t^{-}$is $\left.\frac{1}{2}\right)$ that $\operatorname{Pr}\left[h_{1} \mid t^{-}\right]=\frac{1}{2}(1-\mu) / D$ and $\operatorname{Pr}\left[h_{2} \mid t^{-}\right]$ $=(1-\pi) \mu \operatorname{Pr}\left[z \in Z_{P}\right] / D$, where $D=\frac{1}{2}(1-\mu)+(1-\pi) \mu \operatorname{Pr}[z \in$ $\left.Z_{P}\right]$.

Let $g\left(z \mid t^{-}\right)$denote the conditional density of $z$, given that $t^{-}$is observed. We have

$$
\begin{aligned}
g\left(z \mid t^{-}\right) & =\frac{\operatorname{Pr}\left[t^{-} \mid z\right] f(z)}{\int_{z>0} \operatorname{Pr}\left[t^{-} \mid z\right] f(z) d z+\int_{z<0} \operatorname{Pr}\left[t^{-} \mid z\right] f(z) d z} \\
& =\frac{\operatorname{Pr}\left[t^{-} \mid z\right] f(z)}{\frac{1}{2}},
\end{aligned}
$$


where the last step follows from the assumption that $F(z)$ is symmetric around zero. This implies that $g\left(z \mid t^{-}\right)=(1-\pi) f(z) / \frac{1}{2}$ if $z>0$, and $g\left(z \mid t^{-}\right)=\pi f(z) / \frac{1}{2}$ if $z<0$. Thus, $E\left[z \mid t^{-}, h_{1}\right]=\left[(1-\pi) \int_{z>0} z f(z)\right.$ $\left.d z+\pi \int_{z<0} z f(z) d z\right] / \frac{1}{2}$, which reduces to $E\left[z \mid t^{-}, h_{1}\right]=-(2 \pi-1)$ $E[z \mid z>0]$, again using the assumption that the distribution is symmetric. Thus, the first term in the r.h.s. of $(9)$ is $-\frac{1}{2}(1-\mu)(2 \pi-1)$ $E[z \mid z>0] / D$.

Next, note that $E\left[z \mid t^{-}, h_{2}\right]=E\left[z \mid z \in Z_{P}\right]$, so that the second term in the r.h.s. of (9) is $\mu(1-\pi) \operatorname{Pr}\left[z \in Z_{P}\right] E\left[z \mid z \in Z_{P}\right] / D$. Combining these terms and substituting into (9), we get the l.h.s. of expression (2) (divided by $D$, which is positive). Thus, if this is negative, $N$ will oppose the alternative being introduced, and if it is positive, he will support it, given that his information is $t^{-}$. It can be shown exactly similarly that if his information is $t^{+}$, the expected gain in firm value from the alternative is positive, so that he will support $L$.

Proof of Proposition 3. We first restrict $L$ to a bid of $b^{*}(\alpha)$ and show that the proposed strategies constitute an equilibrium.

Note that in the proposed equilibrium, the conditions of Proposition 2 and Corollary 1 are satisfied, so the bid $b^{*}(\alpha)$ will succeed with probability 1 . Note also that from Proposition 1 it follows that in this equilibrium, since the uninformed $L$ stays out, $N$ will vote with $L$, so the proxy succeeds with probability 1 . Thus, we have to show that the strategies of the informed and uninformed $L$ are as claimed. The payoff to an informed $L$ from a tender offer at an offer price of $b^{*}(\alpha)$ is

$\Pi^{T}(z, \alpha)=0.5(z+q)-(0.5-\alpha) b^{*}(\alpha)-\alpha q-c_{T}$

and that from the proxy is

$\Pi^{P}(z, \alpha)=\alpha z-c_{P}$

We already know from the definition of $z_{m}^{\mathrm{A}}$ that an $L$ that draws $z_{m}^{\mathrm{A}}$ is indifferent between these two payoffs in the proposed equilibrium. The derivative of $\Pi^{T}(z, \alpha)$ with respect to $z$ is 0.5 , while that of $\Pi^{P}(z, \alpha)$ is $\alpha<0.5$. Hence, all types with $z \geq z_{m}^{\mathrm{A}}$ will prefer a tender offer, while those with $z<z_{m}^{\mathrm{A}}$ will prefer a proxy contest. Obviously, types with $z$ $<z_{l}^{A}$ will stay out, as the expected gain from a proxy contest is negative for them.

Consider now the uninformed $L$. Since $E[z]=0$, the expected gain from a proxy contest is evidently negative in view of the proxy costs. The expected gain from the tender offer is also negative, since $c_{T}>0$ and $b^{*}(\alpha)>0$. Thus, the uninformed $L$ will stay out. 
Consider now bids other than $b^{*}(\alpha)$. For such out-of-equilibrium moves, we have to specify appropriate beliefs. Assume that if any other bid is observed, $z$ is believed to be a random draw from the set $K$ of types whose payoffs are higher, if this bid is accepted, than the equilibrium payoff. If the set $K$ is empty, beliefs do not matter. Thus, these beliefs are credible in the sense of Grossman and Perry. Clearly, no type can benefit from bidding greater than $b^{*}(\alpha)$ even if the bid is accepted. Hence, consider $b<b^{*}(\alpha)$. If we restrict attention to positive bids, we know that the uninformed $L$ will never bid. Let the bid be denoted $q+\delta$, where $\delta$ $<E\left[\tilde{z} \mid \tilde{z} \geq z_{m}^{\mathrm{A}}\right]$. The informed L's who would deviate if the bid were accepted are all those who prefer the tender offer to the proxy contest at the new bid, since the payoff from the proxy contest is not affected. Thus, the lowest $\operatorname{such} z$, say $z^{\prime}$, is given by the following:

$0.5\left(z^{\prime}+q\right)-(0.5-\alpha)(q+\delta)-\alpha q-c_{T}=\alpha z^{\prime}-c_{P}$,

which gives

$\delta-z^{\prime}=\frac{c_{P}-c_{T}}{0.5-\alpha}$.

Since $\delta<E\left[\tilde{z} \mid \tilde{z} \geq z_{m}^{\mathrm{A}}\right]$, it follows from the expression for $z_{m}^{\mathrm{A}}$ [equation (4)] that $z^{\prime}<z_{m}^{\mathrm{A}}$. Hence, from Lemma 1, we have

$E\left[\tilde{z} \mid \tilde{z} \geq z^{\prime}\right]-z^{\prime}>E\left[\tilde{z} \mid \tilde{z} \geq z_{m}^{\mathrm{A}}\right]-z_{m}^{\mathrm{A}}=\frac{c_{P}-c_{T}}{0.5-\alpha}=\delta-z^{\prime}$.

Hence, $E\left[\tilde{z} \mid \tilde{z} \geq z^{\prime}\right]>\delta$. However, if this condition holds, from Proposition 2, shareholders will not tender, and the bid will fail for sure. Consequently, no bids below $b^{*}(\alpha)$ can occur.

It remains to show that no other semipooling equilibrium exists in which $N$ votes with $L$ and that is supported by consistent beliefs. By arguments essentially similar to those made above, it can be shown that it is not optimal for investors to accept bids below $b^{*}(\alpha)$. Hence, consider only $b>b^{*}(\alpha)$ as alternative candidate equilibrium bidding strategies. However, for each such $b$, the set $K$ of types who benefit from a bid of $b^{*}(\alpha)$ if it is accepted is evidently the set $\left[\tilde{z}, z_{m}^{\mathrm{A}}\right]$, and we know then that such a bid will be accepted if $z$ is believed to be a random draw from this set. This upsets the equilibrium.

Proof of Proposition 5. Consider type A equilibrium first.

The market value of the firm in type A equilibrium is given by

$V^{\mathrm{A}}=q+\rho \mu(\operatorname{Pr}[$ proxy $] E[z \mid$ proxy $]+\operatorname{Pr}[$ tender offer $] E[z \mid$ tender offer $])$

$=q+\rho \mu \int_{z_{l}^{\mathrm{A}}}^{\bar{z}} z d F(z)$. 
The market value given that a tender offer is announced is

$V_{T}^{\mathrm{A}}=q+E\left[z \mid z \geq z_{m}^{\mathrm{A}}\right]$,

and that following the announcement of a proxy contest is

$V_{P}^{\mathrm{A}}=q+E\left[z \mid z \in\left[z_{l}^{\mathrm{A}}, z_{m}^{\mathrm{A}}\right]\right]$.

It is immediately clear that $V_{T}^{\mathrm{A}}-V^{\mathrm{A}}>V_{P}^{\mathrm{A}}-V^{\mathrm{A}}$. From equation (12), note also that $V_{T}^{\mathrm{A}}-V^{\mathrm{A}}>0$, and

$V_{P}^{\mathrm{A}}-V^{\mathrm{A}}=\left(\frac{1}{\operatorname{Pr}\left[z \in\left[z_{l}^{\mathrm{A}}, z_{m}^{\mathrm{A}}\right]\right]}-\rho \mu\right) \int_{z_{l}^{\mathrm{A}}}^{z_{m}^{\mathrm{A}}} z d F-\rho \mu \int_{z_{m}^{\mathrm{A}}}^{\bar{z}} z d F$.

For $\rho$ sufficiently small, this is positive.

Next, consider type B equilibrium. The market value of the firm in type $B$ equilibrium is given by

$$
\begin{aligned}
V^{\mathrm{B}}= & +\frac{1}{2}(1-\mu) \rho(2 \pi-1) E[z \mid z>0] \\
& +\mu \rho \pi \int_{z_{l}^{\mathrm{B}}}^{z_{m}^{\mathrm{B}}} z d F(z)+\mu \rho \int_{z_{m}^{\mathrm{B}}}^{\bar{z}} z d F(z),
\end{aligned}
$$

where the second term is the value improvement due to the participation of the uninformed $L$ in the proxy contest and is derived from considerations similar to those in equation (6). The last two terms denote the value improvement associated with an informed $L$ from the proxy contest and tender offer, respectively.

The value of the firm conditional on the tender-offer announcement is

$V_{T}^{\mathrm{B}}=q+E\left[z \mid z \geq z_{m}^{\mathrm{B}}\right]$,

while that following the announcement of a proxy contest is

$V_{P}^{\mathrm{B}}=q+\frac{1}{2}(1-\mu)(2 \pi-1) E[z \mid z-0]+\mu \pi E\left[z \mid z \in\left[z_{l}^{\mathrm{B}}, z_{m}^{\mathrm{B}}\right]\right]$.

Evidently, a sufficient condition for $V_{T}^{\mathrm{B}}-V^{\mathrm{B}}>V_{P}^{\mathrm{B}}-V^{\mathrm{B}}$ is that

$\max \left\{E\left[z \mid z \in\left[z_{l}^{\mathrm{B}}, z_{m}^{\mathrm{B}}\right]\right], E[z \mid z>0]\right\}<E\left[z \mid z \geq z_{m}^{\mathrm{B}}\right]$,

which is clearly satisfied. It can be shown as before that the former is always positive, and the latter is positive for $\rho$ sufficiently small.

Proof of Proposition 6. The sign of the following partial derivatives can be readily derived from equations (5) and (4) and Lemma 1 (see Fig. 1): 
$\frac{\partial z_{m}^{\mathrm{A}}}{\partial c_{P}}<0, \quad \frac{\partial z_{m}^{\mathrm{A}}}{\partial c_{T}}>0, \quad \frac{\partial z_{m}^{\mathrm{A}}}{\partial \alpha}<0$

and

$\frac{\partial z_{l}^{\mathrm{A}}}{\partial c_{P}}>0, \quad \frac{\partial z_{l}^{\mathrm{A}}}{\partial c_{T}}=0, \quad \frac{\partial z_{l}^{\mathrm{A}}}{\partial \alpha}<0$.

1(i): The probability of a tender offer is $\rho \mu\left[1-F\left(z_{m}^{\mathrm{A}}\right)\right]$, and is thus negatively related to $z_{m}^{\mathrm{A}}$. The results are therefore immediate from equations (18) and (17).

1(ii): We have, letting $y$ denote either $c_{P}, c_{T}$, or $\alpha$,

$\frac{\partial\left(V_{T}^{\mathrm{A}}-V^{\mathrm{A}}\right)}{\partial y}=\frac{f\left(z_{m}^{\mathrm{A}}\right)}{1-F\left(z_{m}^{\mathrm{A}}\right)}\left(E\left[z \mid z \geq z_{m}^{\mathrm{A}}\right]-z_{m}^{\mathrm{A}}\right) \frac{\partial z_{m}^{\mathrm{A}}}{\partial y}+\rho \mu z_{l}^{\mathrm{A}} f\left(z_{l}^{\mathrm{A}}\right) \frac{\partial z_{l}^{\mathrm{A}}}{\partial y}$.

The results follow immediately from equations (18) and (17).

2(i): The probability of a proxy challenge is $\rho \mu\left[F\left(z_{m}^{\mathrm{A}}\right)-F\left(z_{l}^{\mathrm{A}}\right)\right]$. The results then follow immediately from equations (18) and (17).

2(ii): We have, letting $y$ denote either $c_{P}, c_{T}$, or $\alpha$,

$$
\begin{aligned}
\frac{\partial\left(V_{P}^{\mathrm{A}}-V^{\mathrm{A}}\right)}{\partial y}= & -\frac{f\left(z_{m}^{\mathrm{A}}\right)}{F\left(z_{m}^{\mathrm{A}}\right)-F\left(z_{l}^{\mathrm{A}}\right)}\left(E\left[z \mid z \in\left[z_{l}^{\mathrm{A}}, z_{m}^{\mathrm{A}}\right]\right]-z_{m}^{\mathrm{A}}\right) \frac{\partial z_{m}^{\mathrm{A}}}{\partial y} \\
& +\frac{f\left(z_{l}^{\mathrm{A}}\right)}{F\left(z_{m}^{\mathrm{A}}\right)-F\left(z_{l}^{\mathrm{A}}\right)}\left(E\left[z \mid z \in\left[z_{l}^{\mathrm{A}}, z_{m}^{\mathrm{A}}\right]\right]-z_{l}^{\mathrm{A}}\right) \frac{\partial z_{l}^{\mathrm{A}}}{\partial y} \\
& +\rho \mu z_{l}^{\mathrm{A}} f\left(z_{l}^{\mathrm{A}}\right) \frac{\partial z_{l}^{\mathrm{A}}}{\partial y} .
\end{aligned}
$$

Proof of Proposition 7. The proof is immediate from the expression for firm value in (12) and from equations (18) and (17).

Proof of Proposition 8. The market value of the firm in type B equilibrium is given in equation (15). The success probability of a proxy in type $\mathrm{B}$ equilibrium is given by

$$
\begin{aligned}
\chi(\mu, \pi)=\frac{\mu \operatorname{Pr}\left[z \in\left[z_{l}^{\mathrm{B}}, z_{m}^{\mathrm{B}}\right]\right]}{\mu \operatorname{Pr}\left[z \in\left[z_{l}^{\mathrm{B}}, z_{m}^{\mathrm{B}}\right]\right]} & +1-\mu \\
& \quad+\frac{1-\mu}{\mu \operatorname{Pr}\left[z \in\left[z_{l}^{\mathrm{B}}, z_{m}^{\mathrm{B}}\right]\right]+1-\mu} \cdot \frac{1}{2},
\end{aligned}
$$

since the proxy succeeds with probability $\pi$ when it is initiated by an informed shareholder $(z>0)$, whereas when it is initiated by an uninformed shareholder, its success probability is $\frac{1}{2}$.

The comparative static results utilize signs of partial derivatives $\partial z_{m}^{\mathrm{B}} / \partial y$ and $\partial z_{l}^{\mathrm{B}} / \partial y$, where $y$ is $c_{P}, c_{T}$, or $\alpha$. The signs of these partial derivatives are the same as the corresponding ones for type A equilib- 
rium given in equations (17) and (18). In addition, we have $\partial z_{m}^{\mathrm{B}} / \partial \pi>$ 0 and $\partial z_{l}^{\mathrm{B}} / \partial \pi<0$.

The results now follow from standard comparative static analysis. We prove part 1 as an illustration: We have

$\frac{\partial V^{\mathrm{B}}}{\partial c_{P}}=-\mu \rho(1-\pi) z_{m}^{\mathrm{B}} f\left(z_{m}^{\mathrm{B}}\right) \frac{\partial z_{m}^{\mathrm{B}}}{\partial c_{P}}-\mu \rho \pi z_{l}^{\mathrm{B}} f\left(z_{l}^{\mathrm{B}}\right) \frac{\partial z_{l}^{\mathrm{B}}}{\partial c_{P}}$.

The first term is positive, but the second is negative; hence the effect is ambiguous in general. However, for $\pi$ close to one, the second term will dominate. The claim about the success probability can be easily verified.

Proof of Proposition 9. Notice the following for $\beta \leq 1$ : The probability that a proxy will be initiated in a type A equilibrium is $\rho\left[F\left(z_{m}^{\mathrm{A}}(\beta)\right)-\right.$ $\left.F\left(z_{l}^{\mathrm{A}}(\beta)\right)\right]$, where $z_{m}^{\mathrm{A}}(\beta)$ represents the $z$ at which $L$ is indifferent between a proxy contest and a tender offer and is given by

$\frac{0.5-\alpha}{0.5-\alpha \beta} E\left[\tilde{z} \mid \tilde{z} \geq z_{m}^{\mathrm{A}}(\beta)\right]-z_{m}^{\mathrm{A}}(\beta)=\frac{c_{P}-c_{T}}{0.5-\alpha \beta}$,

and $z_{l}^{\mathrm{A}}(\beta)$ is the lowest $z$ at which $L$ participates in a proxy contest and is given by

$z_{l}^{\mathrm{A}}(\beta)=\frac{c_{P}}{\alpha \beta}$.

Moreover, the firm value in type A equilibrium is given by

$V^{\mathrm{A}}(\beta)=q+\mu \rho\left(\beta \int_{z_{l}^{\mathrm{A}}(\beta)}^{z_{m}^{\mathrm{A}}(\beta)} z d F+\int_{z_{m}^{\mathrm{A}}(\beta)}^{\bar{z}} z d F\right)$.

That a lower $\beta$ leads to less success for proxy challenges in type A equilibrium is obvious. It is also immediate from the expressions for $z_{m}^{\mathrm{A}}(\beta)$ and $z_{l}^{\mathrm{A}}(\beta)$ that the former is increasing and the latter is decreasing in $\beta$, so that the probability of a proxy contest, given by $\rho\left[F\left(z_{m}^{\mathrm{A}}(\beta)\right)-\right.$ $\left.F\left(z_{l}^{\mathrm{A}}(\beta)\right)\right]$, is decreasing in $1-\beta$, the degree of management bias. Differentiating the expression for $V^{\mathrm{A}}(\beta)$ w.r.t. $\beta$, we get

$$
\begin{aligned}
\frac{\partial V^{\mathrm{A}}}{\partial \beta}= & \rho \mu\left(\int_{z_{l}^{\mathrm{A}}(\beta)}^{z_{m}^{\mathrm{A}}(\beta)} z d F-(1-\beta) z_{m}^{\mathrm{A}}(\beta) f\left(z_{m}^{\mathrm{A}}(\beta)\right) \frac{\partial z_{m}^{\mathrm{A}}(\beta)}{\partial \beta}\right. \\
& \left.-\beta z_{l}^{\mathrm{A}}(\beta) f\left(z_{l}^{\mathrm{A}}(\beta)\right) \frac{\partial z_{l}^{\mathrm{A}}(\beta)}{\partial \beta}\right) .
\end{aligned}
$$

Notice that $\partial z_{m}^{\mathrm{A}}(\beta) / \partial \beta>0$ and $\partial z_{l}^{\mathrm{A}}(\beta) / \partial \beta<0$, so that in general the sign of this derivative is ambiguous. However, for $\beta$ sufficiently 
close to one, the middle term becomes small and the derivative is positive.

Proof of Proposition 10. To prove this result, the following lemma is useful:

LEMMA 2: For $\pi<1$,

(i) $z_{l}^{\mathrm{B}}(\beta)>z_{l}^{\mathrm{A}}(\beta)$, and

(ii) $z_{m}^{\mathrm{B}}(\beta)<z_{m}^{\mathrm{A}}(\beta)$.

Proof. Note that the cutoff $z$ at which $L$ is indifferent between a tender offer and a proxy contest is now given by

$\frac{0.5-\alpha}{0.5-\alpha \beta \pi} E\left[\tilde{z} \mid \tilde{z} \geq z_{m}^{\mathrm{B}}(\beta)\right]-z_{m}^{\mathrm{B}}(\beta)=\frac{c_{P}-c_{T}}{0.5-\alpha \beta \pi}$,

and the lowest $z$ for which a proxy challenge is viable is given by

$z_{l}^{\mathrm{B}}(\beta)=\frac{\mathcal{C}_{P}}{\alpha \beta \pi}$.

Thus, (i) is immediate. To see (ii), note that $z_{m}^{\mathrm{B}}(\beta)=z_{m}^{\mathrm{A}}(\beta)$ for $\pi=1$, and $z_{m}^{\mathrm{B}}(\beta)$ is increasing in $\pi$.

Notice now that so long as A2 holds, tender offers will be used with positive probability in both equilibria. The proposition then follows from the fact that by virtue of Lemma 2, assumption A4 implies $\mathrm{A} 3$, so that a nondegenerate type A equilibrium exists whenever a nondegenerate type $B$ exists. However, for type B to exist, even when A1, A2, and A4 hold, two additional conditions-equation (2) and the participation constraint for the uninformed $L-$ need to be satisfied. For example, for $\mu=1$, condition (2) will not hold; yet, type A equilibrium will exist, since its existence is independent of $\mu$.

Proof of Proposition 11(i). The Firm value in type B equilibrium for $\beta \leq 1$ is

$$
\begin{aligned}
V^{\mathrm{B}}(\beta)= & q+\beta \frac{1}{2}(1-\mu) \rho(2 \pi-1) E[z \mid z>0] \\
& +\beta \mu \rho \pi \int_{z_{l}^{\mathrm{B}}}^{z_{m}^{\mathrm{B}}} z d F(z)+\mu \rho \int_{z_{m}^{\mathrm{B}}}^{\bar{z}} z d F(z) .
\end{aligned}
$$

We can rearrange this expression as

$V^{\mathrm{B}}(\beta)=q+\frac{1}{2} \beta \rho(1-\mu)(2 \pi-1) E[z \mid z>0]-(1-\pi) \beta \rho \mu \int_{z_{l}^{\mathrm{B}}(\beta)}^{z_{m}^{\mathrm{B}}(\beta)} z d F$ 


$$
+\beta \rho \mu \int_{z_{l}^{\mathrm{B}}(\beta)}^{z_{m}^{\mathrm{B}}(\beta)} z d F+\rho \mu \int_{z_{m}^{\mathrm{B}}(\beta)}^{\bar{z}} z d F
$$

Thus, comparing with the expression for the market value of the firm in type A equilibrium given in equation (20), we have

$$
V^{\mathrm{B}}(\beta) \gtreqless V^{\mathrm{A}}(\beta)
$$

as

$$
\begin{array}{r}
\beta\left(\frac{1}{2}(1-\mu)(2 \pi-1) E[z \mid z>0]-\mu(1-\pi) \int_{z_{l}^{\mathrm{B}}(\beta)}^{z_{m}^{\mathrm{B}}(\beta)} z d F(z)\right) \\
\gtrless \beta \mu \int_{z_{l}^{\mathrm{A}}(\beta)}^{z_{l}^{\mathrm{B}}(\beta)} z d F-\mu(1-\beta) \int_{z_{m}^{\mathrm{B}}(\beta)}^{z_{m}^{\mathrm{A}}(\beta)} z d F .
\end{array}
$$

Notice that the expression in large parentheses on the 1.h.s. of (21) is the same as the negative of the l.h.s. of (2). Call it $\Delta$. Thus, type B equilibrium exists iff $\Delta$ is positive.

Notice now from Lemma 2 that both terms in the r.h.s. of (21) are positive: hence, the r.h.s. in general is of ambiguous sign.

Consider first the case in which the r.h.s. is positive (this happens for $\beta$ sufficiently close to 1 ). Then the r.h.s. of (21) is increasing in $\mu$. Also, the 1.h.s. is decreasing in $\mu$. Moreover, at $\mu=0$, for $\pi>\frac{1}{2}$, the 1.h.s. is positive and clearly exceeds the r.h.s., which is zero. Hence, part (a) of the proposition follows.

Next, suppose the r.h.s. of (21) is negative. Since $\Delta>0$ whenever type B equilibrium exists, type B dominates for $\mu \leq \mu^{*}$.

Part (b) follows from the fact that at $\pi=1$, the 1.h.s. is positive but the r.h.s. is zero, as $z_{l}^{\mathrm{A}}(\beta)=z_{l}^{\mathrm{B}}(\beta)$ and $z_{m}^{\mathrm{B}}(\beta)=z_{m}^{\mathrm{A}}(\beta)$.

Proof of Proposition 11(ii). That tender offers are more frequent in type $B$ equilibrium follows immediately from Lemma 2. From the same lemma, proxy contests would be less frequent at $\mu=1$ at type B equilibrium than at type $\mathrm{A}$ if type $\mathrm{B}$ equilibrium were viable; however, at $\mu$ $=1$ condition (2) does not hold. By continuity, there exists $\mu^{P}$ such that proxy contests would be less frequent iff $\mu \geq \mu^{P}$. The rest is immediate.

\section{REFERENCES}

Bikhchandani, S., D. Hirshleifer, and I. Welch, 1992, "A Theory of Fads, Fashions, Custom, and Cultural Change as Information Cascades," Journal of Political Economy, 100, 992-1026.

Boot, A., 1992, “Why Hang On to Losers: Divestitures and Takeovers," Journal of Finance, 47, 1401-1423. 
Brickley, J., R. Lease, and C. Smith, Jr., 1988, “Ownership Structure and Voting on Antitakeover Amendments," Journal of Financial Economics, 20, 267-291.

Chowdhry, B. and N. Jegadeesh, 1994, "Pre-tender Offer Share Acquisition Strategy in Takeovers," Journal of Financial and Quantitative Analysis, 29(1), 117-129.

DeAngelo, H. and L. DeAngelo, 1989, "Proxy Contests and the Governance of Publicly Held Corporations," Journal of Financial Economics, 23, 29-59.

Harris, M. and A. Raviv, 1988, "Corporate Control Contests and Capital Structure," Journal of Financial Economics, 20, 55-86.

Hirshleifer, D. and A. Thakor, 1994, "Managerial Performance, Boards of Directors and Takeover Bidding," Journal of Corporate Finance, 1(1), 63-90.

— and — 1996, "Corporate Control through Dismissals and Takeovers," Working Paper, University of Michigan.

— and S. Titman, 1990, "Share Tendering Strategies and the Success of Hostile Takeover Bids," Journal of Political Economy, 98(2), 295-324.

Jarrell, G.A. and M. Bradley, 1980, "The Economic Effects of Federal and State Regulations of Cash Tender Offers," Journal of Law and Economics, 23(2), 371-407.

— and A. Poulsen, 1987, "Bidder Returns," Working Paper, University of Georgia.

- J.A. Brickley, and J. Netter, 1988, "The Market for Corporate Control: The Empirical Evidence since 1980," Journal of Economic Perspectives, 2(1), 49-68.

Jensen, M.C., 1986, "Agency Costs of Free Cash Flow, Corporate Finance and Takeovers," American Economic Review, 76, 323-329.

Mulherin, J.H. and A.B. Poulsen, 1995, "Proxy Contests, Shareholder Wealth and Operating Performance: An Analysis of the 1980s," Working Paper, University of Georgia.

Pound, J., 1988, "Proxy Contests and the Efficiency of Shareholder Oversight," Journal of Financial Economics, 20, 237-265.

- 1989, "Shareholder Activism and Share Values: The Causes and Consequences of Countersolicitations against Management Antitakeover Proposals," Journal of Law and Economics, 32, 357-379.

- 1991, "Proxy Voting and the SEC: Investor Protection versus Market Efficiency," Journal of Financial Economics, 29, 241-285.

- 1992, "The Rise of the Political Model of Corporate Governance and Corporate Control," Working Paper, John F. Kennedy School of Government, Harvard University.

Shleifer, A. and R.W. Vishny, 1986, "Large Shareholders and Corporate Control," Journal of Political Economy, 94, 461-488.

— and - 1989, "Management Entrenchment: The Case of Manager-Specific Investments," Journal of Financial Economics, 25, 123-139.

Sridharan, U.V. and M. Reinganum, 1995, "Determinants of the Choice of the Hostile Takeover Mechanism: An Empirical Analysis of Tender Offers and Proxy Contests," Financial Management, 24, 57-67.

Van Nuys, K., 1993, "Corporate Governance through the Proxy Process: Evidence from the 1989 Honeywell Proxy Solicitation," Journal of Financial Economics, 34, 101-132. 